\title{
Heads of state to decide on EU research funds
}

Paris. The next five-year Framework research programme of the European Union (EU), scheduled to start next year, is hanging in the balance this week after the council of research ministers failed to agree at a meeting in Brussels on Monday to its proposed budget of ECU13.1 billion (US\$14.8 billion).

The failure could mean that the long approval process may have to be repeated in 1995. Elections to the European Parliament will be held next June, and the EU therefore only has a short window in which to complete the complex approval procedure if the budget is to receive endorsement from the present Parliament (see Nature, 365, 775; 1993)

In a last-minute bid to salvage the programme, the meeting therefore accepted a proposal from Belgium - the current president of the council - that the budget question be resolved by Europe's heads of state, who are meeting in Brussels today ( 9 December) and tomorrow.

The research ministers did agree that almost 90 per cent of the budget be spent on a research and development programme in seven categories: information and communications technologies ( 28.2 per cent), industrial technology (16 per cent), environment ( 9 per cent), life sci- ences (13.1 per cent), non-nuclear energy (18.15 per cent), transport (2 per cent) and socioeconomics 0.85 per cent).

They also agreed that the remaining money should be divided between international cooperation ( 4 per cent) and human capital and mobility (6.2 per cent). Despite increasing calls for the EU to spend more on technology transfer, the ministers demanded a cut in the 4.6 per cent of the total which the commission proposed for this area to 2.5 per cent.

Observers are optimistic that Europe's heads of state will agree to a figure close to ECU13.1 billion currently being proposed on Friday. But the move confirms that although the research ministers, such as Paul Kruger of Germany, generally support the commission's proposed budget, their hands appears to be tied by their finance ministers.

Optimism is partly due to the fact that research has moved up the European agenda. In particular, this week's summit is being held to discuss a policy document from Jacque Delors, the president of the commission, on employment, growth and competitiveness, which gives considerable importance to the support of research and development.

But even if the heads of state do agree on a budget for the Fourth Framework, the programme may nonetheless be delayed, as the research ministers also failed to agree on the proposed ECU1.14 billion funding for the EU's four Joint Research Centres (JRC).

Member states have long criticized the JRCs for their relatively low productivity. Together with the European Parliament, several states have argued that it is "entirely illogical" for the JRCs to be given money before it is decided what work they are going to do with it. They want the JRCs to bid for a slice of each programme like any other research group.

Conflict on this issue was not expected at Monday's meeting of research ministers. The parliament had already accepted a compromise by accepting that the JRCs be funded in the Fourth Framework on condition that they are evaluated before the fifth.

The research ministers, however, said on Monday that they want to tackle the issue now. They are pushing for a different outcome, under which the JRCs would receive some money up front to carry out activities which they are in a unique position to address, but will be required to bid with others for any other research funds.

Declan Butler

\section{China learns cautionary tale from Mongolian 'fossils'}

Beijing. Chinese geologists are facing up to the implications of finding out that the discovery three years ago of a huge fossil belt in the far north of the country turns out to have been based on the misinterpretation of geological samples.

The disputed discovery was announced in 1990 by Wang Dong-Fang, Liu XiaoLiang and other researchers at the Chinese Academy of Geological Sciences' Shenyang Institute of Geology and Mineral Resources. In two published papers, they claimed to have discovered fossilized remains of a new fauna, which they named Qinghezhen, in a $200-\mathrm{km}-$ long belt in a region known as the inner Mongolian land axis.

Calling the fossils "small shelly fossils" or "small shells", the authors claimed that the fauna dated from the Precambrian era. They also concluded that the inner Mongolian land axis had not always existed as a continuous land mass, a conclusion which, if confirmed, would have overturned all previous thinking about the geological evolution of northern China.

Soon after the publication of the two papers, various geologists, including three from the Shenyang Institute, raised doubts about the authenticity of the reported fossils. But rather than going back to check - or answering questions raised by their critics - the authors of the original papers published two more, drawing further conclusions

Such actions only increased the determination of critics to find the true nature of the objects in question. Chen Menge, a research professor with the Chinese Academy of Sciences' Institute of Geology in Beijing, decided to look closely at what had happened when geological specimens collected by the scientists were treated in the laboratory.

According to a report of his investigation, published in the journal Scientia Geologica Sinica, Chen concluded that

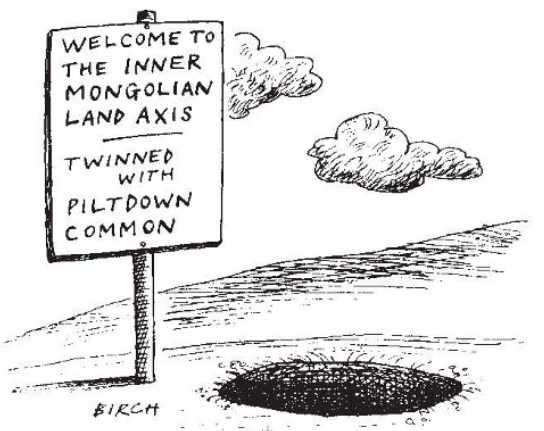

the so-called fossils had been formed during this treatment. He points out that precipitation of minerals in the solution surrounding air bubbles can create fragments that look like fossils.

The final verdict was passed April this year at the annual meeting of the Chinese Palaeontology Speciality Committee. The fossils were certified as false, and the conclusions that had been drawn from them were nullified.

Simon Conway Morris, reader in evolutionary palaeobiology at the Department of Earth Sciences at the University of Cambridge, England, suggests Western scientists should not be too censorious. Chinese palaeontologists, he says, have made good progress with unravelling the story of early skeletal fossils from the Cambrian era, but the inner Mongolian fossils "aren't the first victim of sudden revision."

"In the past supposed Cambrian microfossils from China have been shown to be modern seeds, and the current state of taxonomy is still pretty ramshackle," says Conway Morris. But, he adds, "even if Wang Dong-Fang and his colleagues have made a mistake, it is high time the more complex tectonic belts were searched for early fossils."

You Qin Li 